\title{
A RETERRITORIALIZAÇÃO DO RETORNADO CEARENSE: UMA PERSPECTIVA GEOGRÁFICA
}

\author{
THIAGO ROMEU \\ Universidade Federal de Campina Grande
}

\section{Introdução}

A migração, aparentemente, não é uma tendência do ser humano, mas, sempre que dificuldades assolam a vida humana, uma possibilidade constantemente presente é a saída do seu lugar de residência. Ainda hoje, o sonho de deixar a pobreza, a calamidade, a perseguição e as recorrentes privações levam muitas pessoas a deixar seus lugares de origem, num mundo em que as comunicações e os transportes, cada dia mais velozes, conduzem mercadorias, pessoas e discursos, numa circulação rápida que tem o próprio mundo como limite geográfico. Percebemos então, por meio de grandes contrastes, as diferenças econômicas e sociais. Ilhas de luxo e prosperidade emergem em mares de miséria. Regiões inteiras são identificadas pela calamidade e pela ausência, algumas se tornando mesmo símbolos destes adjetivos.

O Nordeste, como região-símbolo da miséria e da ausência, constituise ao longo de sua história no lócus "natural" da seca e, consequentemente, num lugar de vida dificultada pelas condições naturais. É, portanto, um polo emissor de migrantes. Esse discurso, que naturaliza a miséria e reafirma a necessidade da migração, foi produzido ao longo dos séculos e reafirmado pela elite política local. A imagem dos retirantes da seca foi, então, cristalizada como a marca dessa região, criada a partir de vínculos tanto com a cultura subalterna como com a cultura dominante (IANNI, 1992), construindo na mentalidade dos poderes públicos e da elite regional a noção de uma necessidade perpétua (CASTRO, 1992), constituindo, consequentemente, uma ideia de ausência absoluta, onde haveria poucos elementos fixadores, nada que motive os indivíduos a desejarem permanecer em seus lugares de origem (ALBUQUERQUE JR., 1999).

$\mathrm{O}$ discurso da necessidade permanente e da exaltação do sertanejo nordestino como "um forte" constituiu no imaginário coletivo uma imagem de que este indivíduo possui caráter resistente, adequado para trabalhos que 
exijam força e pouca qualificação (PÓVOA NETO, 1994), reforçando na mentalidade do sertanejo que há possibilidades reais de um emprego para sua força de trabalho nas cidades para onde migra.

Esta breve introdução acerca da percepção que temos do processo migratório no Nordeste tem por finalidade contextualizar o objeto deste estudo, que é o migrante de retorno, um sujeito associado diretamente a um fenômeno que não é novo nos estudos migratórios, mas o é no que se refere a uma região que tem como uma de suas marcas a emigração. Uma questão que surge é o que estaria motivando tal processo. Nosso intuito, contudo, não é o de responder estritamente a esta questão, mas sim entender como o retornado se reterritorializa em seu lugar de retorno, contribuindo assim para a compreensão das motivações que levam os indivíduos a esse lugar de retorno, que já não é mais o mesmo de origem porque tanto o migrante quanto o lugar já se modificaram.

Sem uma hierarquização preestabelecida, poderíamos dizer que o nosso principal intento é identificar e apontar as implicações que o processo de retorno gera nas territorialidades dos retornados e, por consequência, nos territórios de retorno. Contudo, não nos restringiremos a esse objetivo. Também buscamos identificar elementos que motivam a migração e, posteriormente, o retorno, averiguando as relações entre esses dois fenômenos. Mais especificamente, pretendemos mostrar ainda que a dimensão simbólica no processo de retorno assume cada vez maior importância em relação aos estímulos migratórios. Cabe aqui uma observação importante: durante os trabalhos de campo iniciais verificamos que o discurso e sua dimensão simbólica eram constantemente utilizados para ressaltar a necessidade do retorno. Isso levou à hipótese de que, para além de uma necessidade meramente funcional, o retorno se fundava também em "necessidades" simbólicas. Finalmente, buscamos ainda analisar com que força se dá a apropriação e o uso, por parte dos retornados, da identidade nordestina e da identidade com o estado do Ceará.

O que vincula o migrante ao seu território não se restringe apenas a esta ou aquela esfera da vida, é um misto de todos os aspectos que marcam sua individualidade. No entanto, o lugar de origem se apresenta, muitas vezes, de um modo mitificado ou mesmo mistificado, fazendo do retorno um ato que visa restabelecer uma territorialidade deixada para trás. Tanto o estímulo à migração nordestina quanto o retorno, muitas vezes sobretudo na última década - são gerados não necessariamente pela calamidade ou por recorrentes privações, mas a partir das imagens criadas e projetadas sobre este lugar e as metrópoles do "Sul". 
A investigação se restringiu aos migrantes retornados no Ceará, partindo de uma amostragem em municípios de quatro mesorregiões de planejamento do estado. Na primeira envolveram-se cinco municípios do noroeste cearense (Ipu, Reriutaba, Varjota, Ubajara, São Benedito e Guaraciaba do Norte), na segunda, o município de Canindé, no norte cearense, na terceira, o município de Quixadá, na região dos sertões cearenses e, no sul, o município de Abaiara. Foram realizadas entrevistas com 52 retornados, contatados a partir da rede migratória estabelecida por eles próprios, na qual cada um indica o próximo a ser entrevistado. Também foram entrevistados migrantes cearenses no Rio de Janeiro em duas das localidades que mais os agregam na cidade: as comunidades da Rocinha e de Rio das Pedras.

Durante a pesquisa, buscamos ressaltar a percepção dos sujeitos do processo, os próprios retornados. A metodologia se fundamentou, assim, na abordagem da micro-história e da história oral, tendo na análise de entrevistas qualitativas e na observação empírica do trabalho de campo sua principal ênfase. Neste sentido, tomamos por base os trabalhos de Pedone (2000a, 2000b e 2002).

Mapa 1: Municípios investigados no estado do Ceará

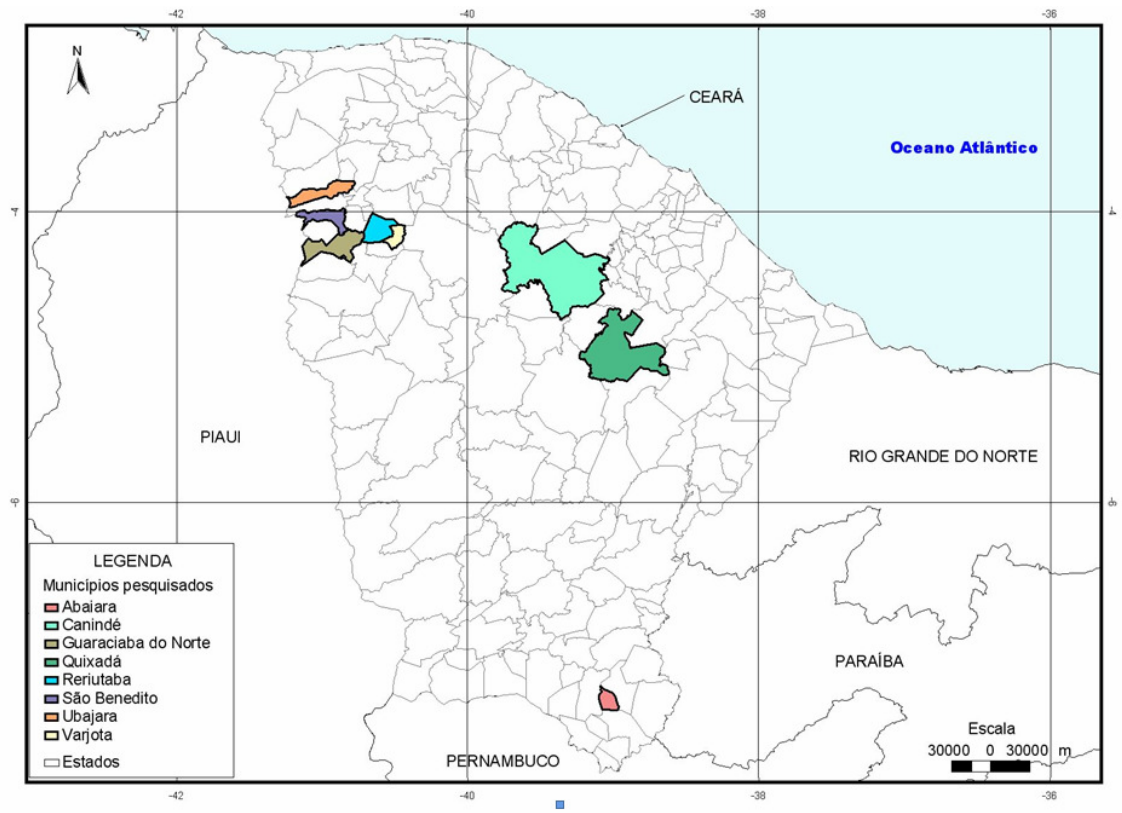


Uma questão de difícil resolução e que requer um estudo de maior profundidade se refere a uma definição genérica desses retornados cearenses. Tais sujeitos reúnem entre si tantas diferenças que qualquer generalização é um processo complexo. Cabe ressaltar, contudo, que os retornados analisados vinculam-se a um espaço com grande influência do meio rural, fixados em municípios do interior cearense, como fica evidente no Mapa 1. Portanto, um elemento importante é o fato de todos possuírem um modo de vida mais adaptado à vida rural, sendo sempre bastante significativo o impacto da metrópole no modo de vida de todos.

Para uma melhor caracterização, percebemos que um elemento agregador geral e que ao mesmo tempo possibilitaria uma melhor diferenciação no grupo seria a faixa etária. Essa abordagem foi também empregada na análise dos retornados espanhóis por Valverde (2004). Os retornados cearenses em nosso estudo foram, assim, divididos em dois grupos etários: o primeiro, chamado de retornados jovens (dos 20 aos 45 anos), e os maduros (acima dessa faixa etária). Essa caracterização não restringiu as diferenças. Ao contrário, expôs outra: "Entre os jovens, a elevada intensidade de retorno está muito relacionada com as migrações múltiplas realizadas durante o período analisado. Trata-se de migrantes entre os quais a duração da residência na região de destino é reduzida"1 (VALVERDE, 2004, p. 5, grifos nossos).

No esforço de identificar a reterritorialização dos retornados cearenses, deparamo-nos com uma impressionante rede de relações e com um fluxo - de sujeitos e emoções - que nos levaram a questionar muitos dos conceitos que previamente estabelecemos acerca dos processos migratórios, inclusive ensaiando uma crítica à forma pouco clara do IBGE de definir a migração de retorno no Brasil. Contudo, o esforço aqui será de expor as nossas conclusões acerca da territorialidade dos retornados obtidas a partir do contato direto com os migrantes em seus lugares de retorno, e como se dá atualmente a reterritorialização do retornado nesses lugares.

\footnotetext{
${ }^{1}$ Tradução livre. No original: "Entre los jóvenes, la elevada intensidad de retorno está muy relacionada con las migraciones múltiples realizadas durante el período analizado. Se trata de migrantes entre los que la duración de residencia en la región de destino es reducida".
} 


\section{Retornados cearenses: multiterritorialidade e reterritorialização}

As experiências do retornado nordestino são sedutoras. Podem provocar ao mesmo tempo sensações de respeito, encantamento, piedade e admiração. Constituem um misto de aventura e drama. A começar pela motivação para a migração, que vai desde a impossibilidade de manter a subsistência no lugar de origem até a realização de todo um projeto de vida. A migração pode levá-lo a enfrentar, em muitas ocasiões, dissabores no lugar de destino, mas também a conhecer novos horizontes geográficos e promover transformações positivas em sua vida. São essas múltiplas vivências, prenhes de experiências territoriais, que tornam a análise do retornado tão rica. Privilegiar o sujeito "retornado" em detrimento do processo "retorno" levou-nos a perceber que contribuiríamos mais para o entendimento dos territórios construídos por estes sujeitos, que não são simples territórios funcionais de re-produção, mas territórios de construção do novo.

$\mathrm{Na}$ tentativa de compreender a reterritorialização do retornado, encontramos a noção de multiterritorialidade, proposta inicialmente por Haesbaert (2004), pois ela parecia esclarecer muitos processos observados, assumindo, gradativamente, uma importância central no trabalho. Utilizando o exemplo dos migrantes como um dos principais agentes na construção de uma multiterritorialidade, o autor a define como:

(...) um processo concomitante de destruição e construção de
territórios mesclando diferentes modalidades territoriais
(como os "territórios-zona" e os "territórios-rede") em
múltiplas escalas e novas formas de articulação territorial.
(2004, p. 32)

Logo, em que medida os retornados podem ser considerados sujeitos multiterritoriais? A concepção de Haesbaert de multiterritorialidade (2004, 2005a e no prelo) ajudou-nos a refletir acerca da importância de vermos tais migrantes como alguns dos principais agentes do processo de multiterritorialização em curso. A noção de multiterritorialidade pode ajudar a explicar a reterritorialização dos retornados, entendendo-se que estes são agentes que renovam a territorialidade no lugar de origem. Eles nos levam à percepção da vivência de múltiplos territórios. Indivíduos como os retornados experimentam claramente mais de um território, o que possibilitaria viver uma multiterritorialidade. Se pensarmos que a experiência de viver em mais de um território de maneira sucessiva, mas manifestando suas características de forma simultânea, é uma "marca" da multiterritorialidade, não seriam os migrantes os agentes multiterritoriais 
mais emblemáticos em nosso tempo? Cremos que sim, afinal, eles carregam consigo experiências territoriais de outros lugares, que diversas vezes também se manifestam no novo território. Isso por si já não seria uma experiência multiterritorial?

Na migração para o lugar de destino - a metrópole —, os migrantes sofrem uma primeira desterritorialização. Na verdade, esta aparente desterritorialização é a primeira parte de uma reterritorialização em novas bases. Como indica Haesbaert:

Nem "fim da espacialidade", inerente à existência do mundo, nem "fim da territorialidade", inerente à condição humana, a desterritorialização é simplesmente a outra face, sempre ambivalente, da construção de territórios (...) Desterritorialização (sempre hifenizada), tal como a multiterritorialização do nosso tempo, carrega sempre a própria multivalência, o múltiplo, o sincrético ou, se quisermos, para usar o termo da moda, uma "condição híbrida". (2004, p. 365)

Nas metrópoles de São Paulo e Rio de Janeiro, os migrantes nordestinos (em especial os cearenses, no nosso caso) chocam-se com novas condições econômicas, políticas e sociais, que também vão influenciar a sua vivência simbólica. Este confronto com a alteridade gera consequências imediatas. Como afirmou um migrante retornado:

... Eu me sentia muito inferior. O pessoal, assim, lá do Rio e eu sendo do Norte, Nordeste, estas coisas. Eu não era muito de me envolver (...) e era muito ruim, solidão, só. E eu ficava pensando: o que é que eu "tô" fazendo aqui, rapaz, sozinho? E minha família toda lá (...) Se ao menos compensasse, eu ganhasse o bastante (...) mas era só aquela coisinha, só dava pra viver lá bem, tal, mas não dava pra fazer uma coisa melhor pra chegar aqui e fazer algo. Era só aquela coisa mesmo (...) Isso que eu ia falar pra você [sobre o que os naturais do Rio lhe diziam]: poxa, tu veio de quê? Tu vai transportado numa mala, num caixote (...) e a maneira de falar?! Aqui (no Ceará) você sabe que é diferente, também o sotaque. Por exemplo: aqui é mangar, aí dizem: onde é que "tá" a manga, que lá é encarnar, "zoar". Poxa, aquilo ali também (...) eu entrava num chororô. E os caras "pegavam no pé". Realmente a gente falava muito errado, eram as palavras totalmente ao contrário (Eudes, 29 anos, retornado jovem do 
Rio de Janeiro e de São Paulo, morador de Varjota entrevista concedida em janeiro de 2006)

Como vimos, a dimensão simbólica da desterritorialização não se manifesta isolada (mesmo porque as dimensões do território se constituem uma através da outra), mas manifesta-se muitas vezes com mais força quando a condição econômica ou política não é favorável ao migrante. Podemos notar que a diferenciação cultural que marcou a trajetória de Eudes, enaltecida no contato com os cariocas, reverteu-se em saudade do lugar de origem, onde estavam aqueles com quem se identificava. Possivelmente essa diferenciação/identificação seria menos evidente se Eudes fosse um empresário bem sucedido financeiramente. Ou seja, a diferença de classe é sempre um elemento marcante na questão da territorialização.

No retorno, o indivíduo "processa" as experiências territoriais vividas no território de imigração com aquelas em que ele territorialmente se reconhece e, ainda, com aquelas que ele estranha no antigo território de origem. Esse reconhecimento/estranhamento leva os retornados a criar ou aplicar estratégias que são influenciadas pelas experiências adquiridas nas suas múltiplas territorialidades. Neste momento é que percebemos o surgimento de uma nova territorialidade, agora efetivamente múltipla, pois mescla as influências territoriais vividas por estes indivíduos.

Mais do que "território" unitário como estado ou condição
clara e estaticamente definida, devemos priorizar assim a
dinâmica combinada de múltiplos territórios ou
"multiterritorialidade", melhor expressa pelas concepções de
territorialização e desterritorialização, principalmente agora
que a(s) mobilidade(s) domina(m) nossas relações com o
espaço. (...) No caso de um indivíduo e/ou grupo social mais
coeso, podemos dizer que eles constróem seus (multi)
territórios integrando, de alguma forma, num mesmo
conjunto, sua experiência cultural, econômica e política em
relação ao espaço. (HAESBAERT, 2004, p. 341)

Ao contrário do que nos levaria a crer, a aparente desterritorialização proporcionada pela dominação dos espaços em detrimento da sua apropriação (Lefebvre, apud HAESBAERT, 2005) mascara a construção de uma nova territorialidade, uma territorialidade híbrida que nem mesmo os próprios migrantes percebem de imediato. $\mathrm{O}$ retorno e as vivências no território de origem é que propiciam a real percepção do quanto o território de imigração contribuiu na construção de uma territorialidade múltipla. 
A mudança na percepção do seu território, as ações sobre o antigo lugar de origem e a mudança no seu próprio modo de ser mostram, por meio de uma reterritorialização com maior ou menor influência da metrópole, o quanto a migração é complexa, o que inclui a manutenção das redes migratórias. Assim, a condição multiterritorial pode assumir um importante papel na explicação da reterritorialização do retornado.

Podemos afirmar, porém, que nem todos os retornados vivenciam da mesma forma a multiterritorialidade. Embora reconheçamos que todo indivíduo é multiterritorial (HAESBAERT, 2004, p. 349), vale ressaltar que a multiterritorialidade dos retornados é acionada como estratégia espacial especialmente durante a reterritorialização no território de retorno. Sendo assim, os retornados apresentam diferentes formas de reterritorialização frente à realidade dos municípios para onde regressam.

Durante a pesquisa de campo, questionávamos os retornados sobre as principais diferenças que percebiam, inclusive na relação com o território, entre eles e os naturais daquele lugar, que nunca haviam migrado. Cada um, partindo das diferentes possibilidades que a metrópole oferece e da inserção dos migrantes neste universo de alternativas, experimenta distintas situações na conformação de sua territorialidade.

Há diferentes níveis de vivência possíveis em relação às múltiplas territorialidades que a metrópole oferece. Níveis que se manifestam também em função da época em que houve a migração, ou seja, há diferenças de experiências territoriais entre os retornados jovens e os maduros, níveis que dependem do grau de vínculo com o lugar de imigração e de origem, da condição de classe em que estão inseridos etc.

As experiências territoriais dos migrantes na metrópole lhes imprimem novas maneiras de perceber e produzir o espaço. Praticamente todos eles veem essa mudança de modo positivo, mesmo que isso esteja apenas implícito nos seus discursos. Podemos fazer esta afirmação ao observarmos que nenhum migrante retornado entrevistado se mostrou totalmente contrário à ideia de uma volta à metrópole, no caso de uma necessidade extrema. Menos ainda os que estão no início da chamada idade economicamente ativa, os quais consideramos como retornados jovens, como definimos anteriormente.

Cabe ressaltar aqui que esses migrantes unem duas realidades muito distintas: a de uma cidade interiorana, por vezes intimamente ligada ao meio rural, à de uma metrópole, onde a paisagem urbana se apresenta de modo muito mais denso e complexo. O contato entre o campo e a cidade na figura do retornado produz novas territorialidades, e nisso reside um outro 
sentido, em que percebemos a multiterritorialidade do migrante: uma territorialidade que mescla aspectos da sua territorialidade rural, ou de uma cidade pequena, com uma territorialidade urbana muito complexa, no contato do migrante com a metrópole. Essas experiências territoriais produzem possibilidades de reterritorialização totalmente novas. Desse modo, podemos perceber o surgimento de uma nova forma de leitura de mundo, de novos modos de vida que parecem transformar os espaços nos quais se reterritorializam.

\section{Retornados, indivíduos multiterritoriais}

A multiterritorialidade, assim, pode ser percebida como um elemento imanente à figura do migrante. Na condição em que se encontra o migrante enquanto retornado, múltiplas territorialidades vêm à tona, e é no antigo território de origem que a multiplicidade de experiências acumuladas poderá ser materializada. A inevitável multiterritorialidade - por menor que seja a intensidade desse "multi" — estará sempre permeada por várias motivações e esperanças, que poderão ser realizadas ou frustradas. Essas motivações surgem sobretudo pelas possibilidades geradas a partir das experiências e pelos recursos (ainda que simbólicos) adquiridos na metrópole e, mais amplamente, ao longo do processo migratório, juntamente com as prováveis novas oportunidades apresentadas nos lugares de origem.

As expectativas dos migrantes em relação ao retorno ao território de origem é um forte indício de que a multiterritorialização do retornado é um processo ativo e em constante transformação. A este respeito, Haesbaert (2004) comenta a multiterritorialidade individual nas metrópoles e a das diásporas. Em ambos os casos, a mobilidade é uma marca fundamental, e é neste movimento constante e de múltiplos ritmos que os territórios se constituem (HAESBAERT, 2004, p.370).

A multiterritorialidade do retornado poderia ser analisada - e somente analisada - a partir dos seus aspectos ao mesmo tempo simbólicos, políticos e econômico-funcionais. No que se refere ao primeiro, podemos afirmar que o migrante ao chegar à metrópole se vê sob uma perspectiva estigmatizada de inferioridade e quando retorna, muitas vezes, já não se percebe mais dessa forma:

(...) Isso é notório [a diferença dos retornados em relação aos que nunca migraram] apesar de eu não ter estudo, mas (...) se eu não tivesse saído, à vista dos que estão aqui... A gente abre 
mais a mente, a gente muda também na maneira de falar, a gente é bem mais desenvolvido do que os que nunca saíram. Eu tenho exemplo (...) dos meus irmãos que nunca saíram. Eles são mais diferentes (...) no sentido de falar, no sentido de raciocinar, de resolver questões. Porque, você sabe, que o nordestino, por natureza é machista (...) já eu, que já tive experiência (...) digo: não gente, não é bem assim (...) no sofrimento aprendi coisas boas (Eudes, morador de Varjota, retornado jovem do Rio de Janeiro e de São Paulo, grifos nossos - entrevista em janeiro de 2006).

É interessante que, em seu processo de reterritorialização, o migrante retornado, mesmo financeiramente na mesma situação, percebe-se simbolicamente diferente em relação aos seus conterrâneos. Ou seja, a transformação financeira, que pode ter sido o elemento fundamental que o levou a migrar, pode até não ocorrer durante a migração, mas sua percepção simbólica do mundo certamente sofrerá transformações importantes. Isso por vezes gera uma espécie de estranhamento entre os que nunca migraram e os que retornaram, conforme apontado por Dias (2000) em sua análise dos retornados cabo-verdianos.

A reterritorialização na metrópole, em muitos casos, obriga o migrante a superar condições adversas, fazendo-o, muitas vezes, suplantar a timidez e o sentimento de inferioridade por um empreendedorismo vigoroso e destemido, ou seja, uma capacidade de transformar limitações, como o medo e a vergonha, em virtudes que possam indicar alguma possibilidade de ascensão econômica e social. Evidentemente, isto não é uma regra, mas há que se considerar também as ações individuais em meio às adversidades sociais mais amplas.

É importante ressaltar também que o lugar de retorno é percebido de maneira dupla pelo migrante retornado. Dias (2000) nos mostra que o espaço vivido experimentado por quem não deixou o território de origem é tipificado pelo migrante retornado. A autora ainda nos mostra que neste jogo de identificação com o lugar está o processamento de múltiplas identidades, ou ainda, podemos acrescentar, de múltiplas territorialidades, o que por vezes gera conflitos:

O emigrante que se afirma definitivamente como francês e é assim visto pelos outros perde seu lugar dentro da sociedade cabo-verdiana. Se, por outro lado, define-se exclusivamente como cabo-verdiano, abre mão do que caracteriza o encanto e o prestígio dos emigrantes, que é justamente sua capacidade 
de estar ao mesmo tempo próximo e distante. (DIAS, 2000, p. 79 , grifos nossos)

A complexidade do processo de retorno e a constituição do sujeito retornado envolve também a questão do território de referência identitária, isto é, aquele ao qual se vincula a principal marca identitária, ou sua referência maior de territorialidade. Apesar da possibilidade, na condição de "multiterritorialidade", de uma identificação com o próprio movimento, no nosso caso a fixação ainda parece falar mais alto do que a mobilidade. Mesmo em suas intensas idas e vindas, percebemos que muitos retornados buscavam sobretudo a fixação em algum lugar, na busca de um mínimo de estabilidade.

Ao percebermos que a maioria dos migrantes entrevistados havia realizado ao menos dois movimentos migratórios para o Sudeste, ou ainda para localidades de outras regiões, a primeira impressão foi de que o migrante se territorializava na própria mobilidade mais do que na fixação. Porém, um olhar mais cuidadoso nos mostrou o contrário.

Nós já moramos no Rio de Janeiro há muitos tempos. Nós "tamos" acostumados a ir no Rio de Janeiro morar lá. Passa dois anos, passa três anos, passa quatro anos. A primeira vez [1958] passamos quatro anos, a segunda vez passamos três anos, a terceira vez moramos dois anos, e as outras vezes todas eu só ia a passeio (...) e as outras vezes ele [o marido, seu Manezinho] ia muitas vezes, mas só trabalhar... Ele ia passava meses lá, três quatro meses e eu ficava. Ele ia só trabalhar. (Dona Teresinha, 75 anos, retornada madura do Rio de Janeiro, moradora de Varjota - entrevista em julho de 2005)

... Eu saí daqui atrás de uma melhora lá. O negócio não foi para conhecer, que sabe que quem viaja daqui para lá (...) a gente padece um pouco. A primeira [viagem ao Rio] foi fácil, passei um mês, arrumei um emprego, mas a segunda já foi muito difícil... Dessa vez, que eu fui [para o Rio], eu fui morar na Rocinha. A última vez, voltei novamente. Aí eu digo assim: agora vai dar certo. Disse papai: "poxa" meu filho, você já tentou um bocado de vezes, não deu certo. É ilusão você só vai é sofrer. Dar preocupação à gente. Foi uma viagem que foi até mais marcante que a primeira, não sei por quê. Agora você vê, foi uma choradeira geral dos meus familiares, mas eu digo: eu vou tentar mais uma vez (...) vai dar certo! (Eudes, entrevista em janeiro de 2006) 
Numa rápida observação destas falas, podemos concluir que o retornado é um indivíduo que tem na mobilidade uma de suas marcas, expresso no movimento que fazem de um lugar ao outro, e que a constância no movimento é o que leva o retornado a uma maior ênfase a sua condição multiterritorial. É como se criasse um território múltiplo, que se reafirma no movimento entre um território-zona e outro. No entanto, as entrevistas nos levaram a outra conclusão: o que realmente parece ocorrer é que o constante movimento cria uma situação de "estresse", um incômodo pela falta de estabilidade: "foi só essa vontade boba da gente ir, na intenção de ficar lá. A gente não se deu lá mesmo, nosso lugar certo é aqui mesmo." (Dona Teresinha, entrevista em janeiro de 2006)

Por outro lado, a "opção" por um ou outro território dependerá sobretudo das condições materiais proporcionadas pela migração. Não depende somente do fato de haver ou não uma identificação com o lugar. Aliás, muitos retornados só retornam na maturidade porque as condições funcionais de subsistência não permitiram um retorno definitivo na juventude.

Pareceu-nos que, para os retornados, a fixação em um local é o que pode permitir a concretização de seus planos e é isto que mantém a esperança. contrariamente, a não fixação leva à frustração pessoal e estimula a nova migração.

Partindo-se das entrevistas realizadas, foi possível constatar que o retornado é também responsável, em alguma medida, por suas ações, buscando realizar seus desejos com determinação, e não vivendo exclusivamente à mercê dos fluxos do mercado e da macro-economia, apesar de estes serem, do ponto de vista funcional, elementos fundamentais na constituição de sua territorialidade. Logo, o sujeito retornado vive sua realidade também como protagonista de sua existência, sem desconsiderarmos, é claro, o papel de agentes como o Estado e os fluxos de capitais. Afinal, o retornado não é só moderno, é "tradicional" também. É local e global simultaneamente.

A não repetição da experiência do retorno faz destes sujeitos agentes que, pela condição de estarem em momento e lugar singulares resultantes dessas múltiplas experiências, inauguram uma nova linguagem, expressa na sua forma de falar, de lidar com o espaço, enfim, numa forma diferente de viver o cotidiano.

Não queremos, contudo, retirar a importância do fator econômico no ato do retorno, tampouco afirmar que a migração só tem como motivadora a ação individual, os impulsos do migrante. A crítica marxista da teoria 
liberal é rica no sentido de mostrar que os migrantes são levados pelos fluxos econômicos a buscar as áreas de maior acúmulo de capital e se submeter à ordem capitalista da acumulação (GAUDEMAR, 1977). Entretanto, esses trabalhadores possuem capacidade de decisão pessoal, que também os transforma em "sujeitos de suas ações", retirando-os da posição equivocada de simples vítima. Podemos dizer que os retornados vivem uma multiterritorialidade que lhes permite reterritorializar-se com mais facilidade nos lugares de retorno, podendo usufruir alguns benefícios experimentados na metrópole, num tempo-espaço não tão "veloz" e fluído.

\section{A reterritorialização do retornado no Ceará}

O processo de migração dos retornados cria novas possibilidades espaço-temporais devido à sua multiplicidade e às várias combinações de territorialidades distintas que aí se reproduzem. Multiterritorialidades que denotam uma constituição múltipla de referências territoriais, ora mais marcadas pela (multi)funcionalidade do território, ora pelos aspectos simbólicos, que, ainda que em intensidades diferentes conforme os indivíduos e/ou grupos, nunca são dissociáveis. Procuraremos agora avaliar a territorialização dos retornados a partir de suas experiências no retorno aos seus lugares de origem.

Nos municípios pesquisados, notamos uma considerável influência das metrópoles do Sudeste, especialmente Rio de Janeiro e São Paulo. Essa influência se estende desde nomes de estabelecimentos até a moda no vestuário, difundida sobretudo via novelas produzidas nessas cidades. Apesar de estarmos conscientes de que, neste segundo caso, a influência muito pouco tem a ver com os retornados, sabemos que sua presença, repleta de valores e comportamentos metropolitanos, reforça o papel da mídia. Podemos dizer, então, que parte dessa influência nos lugares de retorno é dada e/ou fortalecida pelos retornados, especialmente os jovens - estes, sobretudo, por apresentarem à comunidade local uma série de novidades comportamentais, antes pouco ou nada expressivas. Agregam-se a isso os investimentos concretos que muitos desses retornados fazem na busca de reproduzirem ali alguns hábitos metropolitanos, hábitos que, em muitos casos, foram estimulados a partir dos ambientes empresariais em que trabalhavam.

No âmbito econômico, os retornados influenciam no seu espaço de reterritorialização de diversas formas. Uma delas, certamente, é na esfera comercial, que vai dos bens de consumo não duráveis, como alimentos, até a venda de eletrodomésticos, peças, veículos etc. Na maioria das cidades 
pesquisadas, inclusive, é comum vermos migrantes retornados manterem pequenos estabelecimentos comerciais, conhecidos com bodegas ${ }^{2}$ (as tradicionais mercearias), que vendem todo tipo de produto doméstico. $\mathrm{O}$ envolvimento nesse comércio diversificado é quase uma regra entre aqueles que retornaram e foram bem-sucedidos. ${ }^{3}$ Dizemos "quase" porque nem todos os retornados que trazem recursos voltam determinados a investir no comércio - como veremos mais a frente, há outros tipos de iniciativas.

Muitos dos investimentos comerciais legais iniciaram com uma banca de "camelô", fazendo do comerciante um migrante pendular entre sua cidade natal e o "Sul".

Tabela 1. Participação dos retornados no comércio legal

\begin{tabular}{|c|c|c|}
\hline Municípios & № de associados & $\begin{array}{c}\text { \%aproximado de associados } \\
\text { retornados }\end{array}$ \\
\hline Guaraciaba do Norte & 43 & 50 \\
\hline São Benedito & 32 & 30 \\
\hline Ubajara & 48 & 20 \\
\hline
\end{tabular}

Fonte: Câmara dos dirigentes lojistas desses municípios - 2003

O comércio é de tal modo um investimento do retornado que as próprias CDLs (Câmaras de Dirigentes Lojistas) são fundadas e administradas, em muitos casos, por migrantes retornados. ${ }^{4}$ No nosso

${ }^{2}$ Acerca das bodegas é importante dizer que muitas se localizam mais afastadas do centro comercial, servindo mais à população da periferia.

${ }^{3}$ Obviamente, ser bem-sucedido na migração de retorno é algo muito relativo. No entanto, quando especificamos a expressão "bem-sucedido" tentamos expor, a partir das entrevistas, aquilo que os próprios retornados transpareceram sobre esta condição. Em geral, ser "bem-sucedido" é ter, no retorno, uma melhora de vida, ou seja, é retornar com recursos ou com experiência que não obriguem o retornado a trabalhar na tarefa que deixou ao migrar e que lhe oferecia menores condições de sobrevivência.

${ }^{4}$ Não são todos os municípios pesquisados que possuem CDLs, que somente foram encontradas nos municípios de Serra da Ibiapaba, Quixadá e Canindé - talvez por possuírem um comércio mais dinâmico e uma estrutura urbana mais complexa. Nessas 
contato com essas câmaras, verificamos que a diversificação comercial dos municípios é expressão, em muitos casos, das experiências migratórias. Podemos verificar esse fato a partir de alguns retornados comerciantes que contatamos.

Paulo, um dos retornados pesquisados, viveu boa parte do tempo do seu último retorno da venda de salgados, mas sua atividade é informal, ao contrário dos retornados mais abastados. Fazia salgados em sua casa e distribuía em diversos bares e lanchonetes de Varjota logo cedo por meio de uma moto que adquiriu com recursos obtidos na migração anterior. Este migrante estivera até então no Rio de Janeiro três vezes e em São Paulo duas. Nestes lugares, sempre se empregou em bares e lanchonetes, mas foi em São Paulo que aprendeu uma profissão.

\section{(...) [Me empreguei] na ZX Lanches $^{5}$ (...) Eu comecei como ajudante, descascando cebola e trabalhei três anos. Então quando eu saí, já tinha um cargo na firma: já era lancheiro. Já sabia fazer todo tipo de lanche, que é o que consegue me manter hoje (...) mas aprendi lá em São Paulo. (entrevista concedida em janeiro de 2006)}

$\mathrm{Na}$ terceira imigração, que foi direcionada para São Paulo, ele aprendeu também a fazer pizza. Quando retornou, direcionou-se para o comércio: "[no terceiro retorno] trabalhei numa pizzaria aqui na Varjota, entregava pizza de moto (...) e também fazia as pizzas, pizzaiollo, eu fazia e entregava (...) Não deu porque pagava muito pouco". O que Paulo destaca, em consenso com outros retornados, é a diferença de rendimentos. Nas metrópoles, apesar de o custo de vida ser alto, os rendimentos são maiores e isso é um elemento motivador da migração. No caso de Paulo, mesmo empregado, abriu mão do emprego na sua cidade de origem e novamente emigrou, agora pela quarta vez, porém direcionando-se para o Rio de Janeiro. Mas, como era possível prever, não se fixou. Apesar de haver oferta de emprego, afinal de contas, sua intenção na migração era aumentar seus rendimentos, como o custo de vida nas metrópoles era alto, ele retornou:

(...) o melhor emprego que eu consegui na vida todinha foi esse, que foi em prédio [como porteiro] (...) Como lancheiro é

entidades, boa parte dos associados é de empresários retornados. As informações prestadas nos foram fornecidas de modo verbal pelos funcionários das CDLs.

${ }^{5}$ ZX Lanches, nome fictício do estabelecimento. 
bom porque aprende a profissão, mas não dá dinheiro (...) Fui mandado embora [do emprego de porteiro]. Quando eu "tava" indo "pra" rodoviária [comprar a passagem de volta], eu passei em Niterói, na "Biarritz" tinha uma placa: "Precisa-se de lancheiro". Eu perguntei à mulher quanto ela "tava" pagando, ela disse: uma faixa de quatrocentos, quinhentos. Eu não quis, vim-me embora. Mesmo sabendo que era um negócio que podia chegar e no mesmo dia trabalhar, eu não quis mais (...) Eu queria vir embora mesmo e o pouco que eu tinha juntado nesse ano dava "pra" eu vir "pra" cá e botar meu negócio (...) É a segunda fabricazinha que eu boto e as vezes que eu botei só não desenvolveu mais porque eu não tinha aquele capital de giro. (entrevista concedida em janeiro de 2006)

O caso de Paulo e de tantos outros com quem conversamos mostra que, do ponto de vista econômico, ocorre uma reterritorialização nos lugares de origem baseada no comércio, de modo que lhes permita uma nova fixação, mesmo que precária, nestes lugares. No entanto, suas falas ressaltam sempre motivações pessoais, dando a entender que a motivação para o investimento neste ramo se refere sempre a cuidados com a família, o tino comercial e/ou unicamente o desejo de se fixar no lugar de origem. É claro que estas são motivações relevantes e devem ser consideradas como tem sido aqui defendido —, mas o atual contexto socioeconômico das metrópoles, envolvendo fenômenos como o desemprego estrutural, tem sido um motivador preponderante para o retorno. ${ }^{6}$

O que percebemos e gostaríamos de destacar, contudo, é a constituição da multiterritorialidade no processo de reterritorialização do retornado. Haesbaert identifica pelo menos duas leituras da multiterritorialização: "aquela que diz respeito a uma multiterritorialidade 'moderna', zonal ou de territórios de redes, embrionária, e a que se refere à multiterritorialidade 'pós-moderna', reticular ou de territórios-rede propriamente ditos, ou seja, a multiterritorialidade em sentido estrito" (2004, p. 348). Neste sentido, poderíamos nos referir à multiterritorialidade do retornado, sobretudo como sendo esta que o autor denomina de "pósmoderna", pois se condiciona principalmente ao papel das redes na sua configuração.

É bom lembrar que, apesar de haver "um jogo territorial inédito" com o advento das redes informacionais, as redes de transportes continuam tendo importância crescente, na medida em que criam novas possibilidades

${ }^{6}$ Ver, por exemplo, reportagem da "Folha de São Paulo" de 23/04/06, p. 16. 
de jogos territoriais. Obviamente, migrantes laborais, nas condições dos cearenses nas metrópoles do Sudeste, têm menos chances de participar das redes informacionais ou virtuais, porém, cremos que, neste caso, as redes de transportes têm uma importância proeminente no que se refere à complexificação da multiterritorialidade "moderna-pós-moderna" desses migrantes.

Uma reterritorialização do retornado com maior chance de sucesso, ou seja, que não o obrigue a migrar novamente, está diretamente envolvida com as distintas multiterritorialidades por ele vivenciadas. A potencialidade dessas redes (multiterritorais) se torna evidente também no âmbito das atividades econômicas informais, como no caso de Paulo e sua atividade comercial, mas existe ainda outro grupo de retornados que direciona seus capitais para um ramo do qual o Ceará é carente e que, por sinal, se vincula ao aspecto mais concreto das redes, o setor de transportes.

Para haver locomoção entre municípios próximos, ou mesmo entre distritos dentro de um mesmo município, a população depende quase que exclusivamente do transporte alternativo. Isso explica em parte o isolamento a que são submetidos alguns pequenos povoados relativamente próximos dos centros urbanos locais. Apesar de estarem separados por alguns quilômetros do centro, estão isolados devido à ausência de linhas de transporte regular. $\mathrm{O}$ transporte de qualquer mercadoria e de pessoas é feito por meio de pick-ups com a carroceria coberta e com vans. Esses meios de transporte são muito comuns (ver Foto 1), marcando o cotidiano da população local. As pick-ups são abundantes, em virtude da forte demanda e da ausência de fiscalização ou controle sobre esse serviço. Este acaba sendo um destino certo dos recursos de boa parte dos retornados. Seu uso parece substituir, ao menos no âmbito local, o papel dos "paus de arara" do passado.

As vans, contudo, são mais caras e indicam o status do retornado, na medida em que somente aqueles que obtiveram maior "sucesso" migratório podem adquiri-las. Tais veículos, ao contrário das pick-ups, servem exclusivamente para o transporte de passageiros (o que não impede, também, o transporte de cargas consideráveis), possuem ar condicionado e fazem trajetos mais extensos, o que aumenta de forma significativa o valor das passagens.

O ramo dos transportes alternativos, de um modo geral, é dominado por migrantes retornados que, em muitos casos, realizaram a viagem de regresso nos próprios veículos comprados na metrópole, fazendo de sua viagem de retorno também a primeira "lotada". No entanto, mesmo com uma crescente demanda por transportes, outras alternativas econômicas 
podem ser consideradas, e até mesmo uma nova migração, caso o investimento não dê certo.

O comércio também é uma alternativa para aqueles que não obtêm sucesso no investimento no ramo dos transportes. Na verdade, o fracasso neste ramo não é incomum, já que a concorrência cresce e já há retornados e não migrantes que se fixaram no ramo há mais tempo e se sentem os legítimos "proprietários" das linhas, estabelecendo uma atmosfera de rivalidade entre os donos de vans.

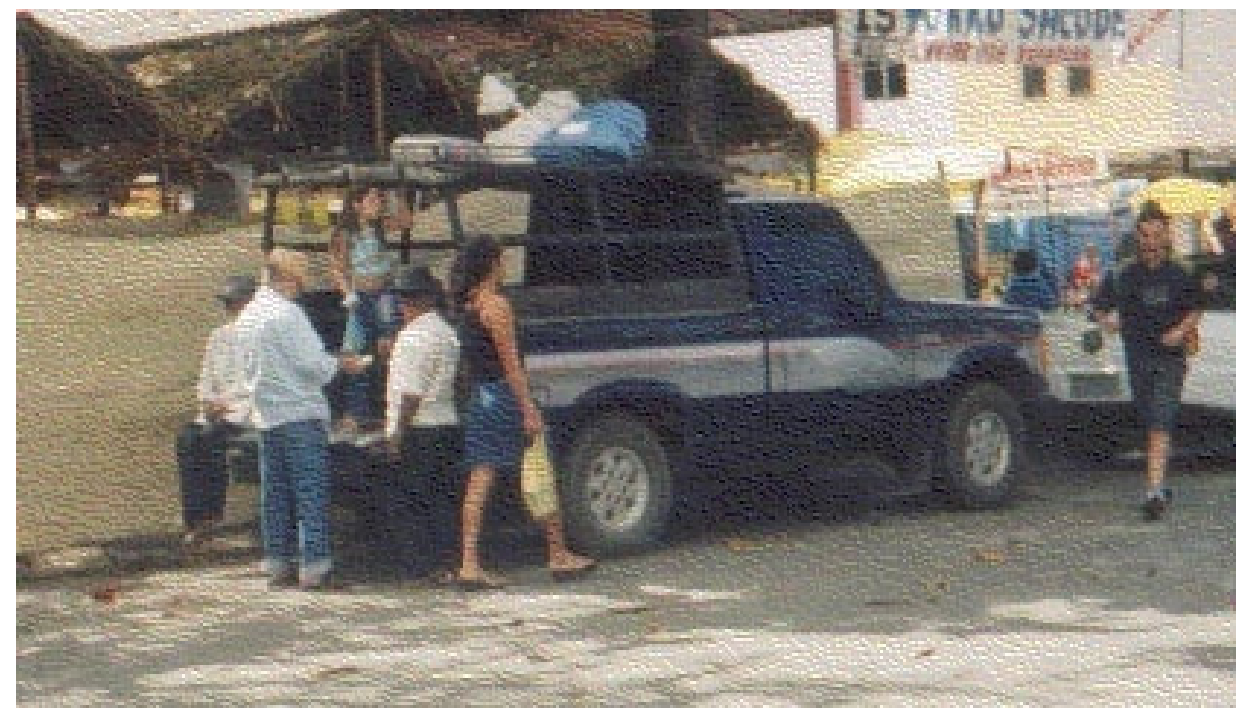

Foto 1: Pick-up típica nas cidades do interior do Ceará. Devido à falta de uma rede de transportes bem estruturada, muitos retornados investem suas economias nestes veículos, tendo em vista a potencial lucratividade (foto do autor / julho de 2003).

Numa dessas viagens intermunicipais, tivemos a oportunidade de entrevistar Raimundo, um retornado do Rio de Janeiro, especificamente da Rocinha, que pode ser considerado um retornado maduro, pois se estabeleceu nessa cidade em 1977, quando ainda tinha 17 anos. Deixou a cidade há 10 anos, tendo permanecido, em uma única vez, 19 anos. Diferentemente de outros retornados, só foi uma vez, permanecendo lá por todo esse tempo. Trabalhava como porteiro em São Conrado e, ao longo da estada no Rio de Janeiro, construiu um pequeno prédio na favela, que está agora alugado. De lá ele tira o reforço de seu orçamento, mas trabalha diariamente fazendo a linha Guaraciaba - São Benedito numa dessas pickups mencionadas. Sua decisão de retornar baseou-se na falta de condições 
que a cidade oferecia para a criação dos seus filhos. Segundo ele, a violência metropolitana não deixaria seus filhos livres da oferta do tráfico de drogas, especialmente porque a Rocinha é um lugar privilegiado para esse tipo de negócio.

É importante ressaltar que, assim como esse entrevistado, outros retornados também apontaram a violência como causa para o retorno. Outros retornados também destacaram a violência como, no mínimo, um grande transtorno metropolitano. Isso evidencia que a violência urbana também é um importante motivador do retorno, juntamente com a precarização de suas condições econômicas na metrópole. Por outro lado, alguns migrantes retornam fortemente influenciados pelas experiências vividas junto ao tráfico de drogas, o que altera bastante a sua "primeira" territorialidade, vinculada ao seu lugar de origem, introduzindo ali novos circuitos ilegais.

Ainda em relação ao transporte alternativo, não se pode deixar de mencionar a grande circulação de motocicletas de aluguel, mais conhecidas como moto-táxis. Neste sentido, as motos de pouca potência são um alvo preferencial dos retornados, que, além de comprarem-nas com os recursos acumulados no local de imigração, ainda as utilizam como um transporte de locação, transformando-as em "meios de vida". De modo semelhante às vans e pick-ups, a concorrência é muito grande - como fica explícito na Foto 2 - e também são comuns histórias de violência entre retornados que tentam se fixar neste ramo e os "donos" mais antigos dos pontos. O desgaste do veículo, junto ao problema da violência entre os envolvidos neste negócio, além dos frequentes roubos, tornam esta atividade um tanto arriscada como investimento.

É interessante notar que há uma íntima relação entre esse tipo de trabalho e a presença de nordestinos, mas não sabemos dizer onde surgiu primeiro, se nos lugares de imigração ou nos lugares de origem. O fato é que, onde há uma concentração de nordestinos nos lugares de imigração, nota-se a proliferação desse tipo de atividade. Podemos perceber isso em algumas favelas do Rio de Janeiro, no subúrbio e nos municípios da região metropolitana desse estado, como São Gonçalo e Itaboraí, para citar apenas alguns casos que nos são mais próximos. 


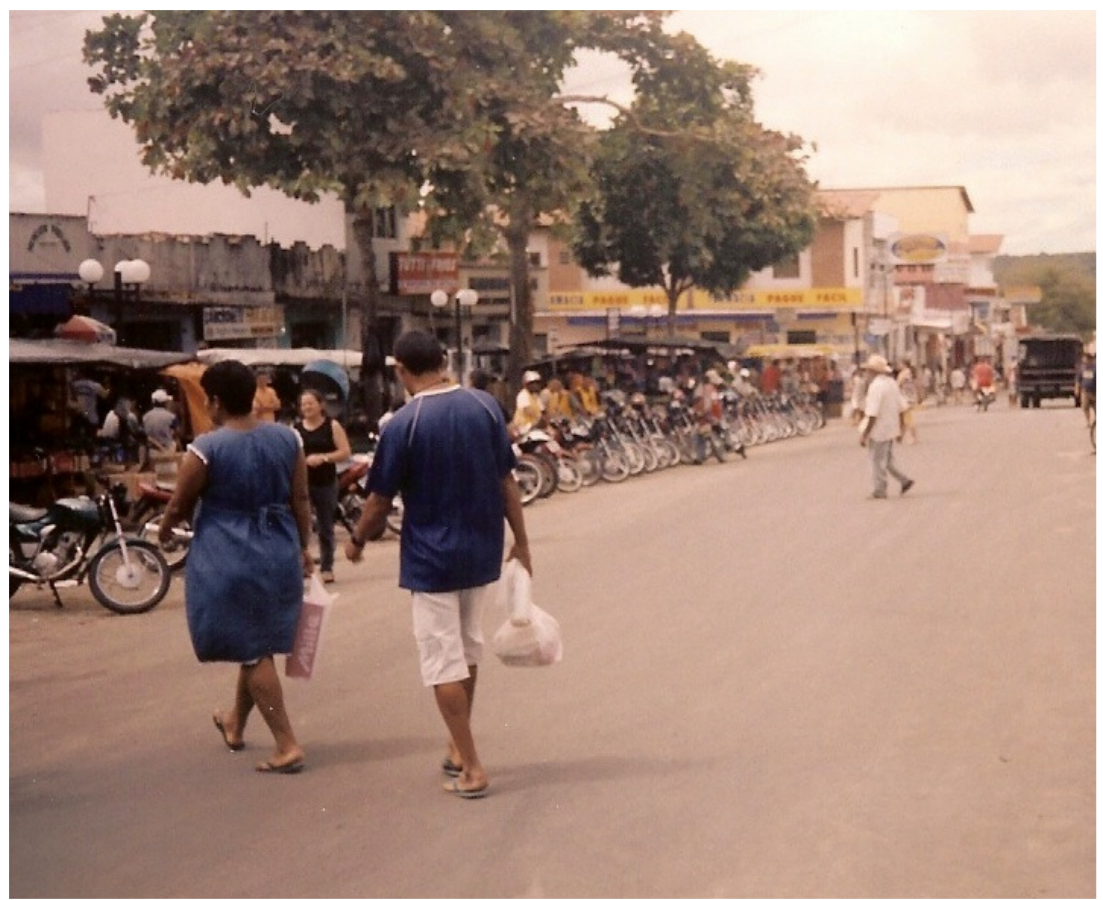

Foto 2: Ponto de moto-táxi em Guaraciaba do Norte (foto do autor / julho de 2003).

Outra atividade que atrai retornados, especialmente os mais maduros, é a agropecuária. Muitos migrantes cearenses, ao retornarem, não conseguem se estabelecer em outro ramo que não seja aquele que deixaram ao emigrar. Em todos os casos de retornados que trabalhavam atualmente na agricultura, verificou-se que a atividade anterior, bem como a sua moradia, estavam na zona rural. Ou seja, não houve uma mudança de domicílio e nem de atividade econômica da urbana para rural - na verdade, ocorre o contrário: o migrante, em muitos casos, deixa a área rural na emigração e, ao retornar, passa a residir no espaço urbano do município de origem, inclusive trabalhando em atividades de comércio e serviços. Porém, outra forma de reterritorialização no lugar de origem é o retorno às atividades agropastoris, que não deixam tão explícito o "nível" de multiterritorialização do retornado, tendo em vista que retorna para a atividade que deixou antes de migrar. De qualquer modo, isto não descarta um certo nível de multiterritorialidade do retornado, que pode se manifestar em outras esferas da vida, além da econômica. 
A agricultura é, sem dúvida, uma atividade econômica muito presente na vida dos municípios do interior do Ceará - em todos aqueles que pesquisamos, esta atividade era minimamente organizada, diferentemente das atividades comerciais, que em poucos municípios tinha uma organização formal. Os sindicatos de trabalhadores rurais são muito procurados por retornados que não tiveram uma formação profissional, não tiveram a oportunidade ou, ainda, não encontraram outra alternativa senão a da atividade econômica que deixaram para trás na emigração. Tais sindicatos têm como função principal garantir direitos, oferecer benefícios de saúde e educação, viabilizar aposentadorias e ser ainda porta-vozes políticos dos trabalhadores rurais. Muitos retornados que não conseguiram obter recursos na migração para o "Sul" voltam para a agricultura buscando se aposentar pelo FunRural, ${ }^{7}$ abandonando todos os laços empregatícios com a metrópole em busca de uma melhoria econômica.

A função de porta-voz político, no entanto, parece ser reforçada quando percebemos que a vinculação com o sindicato leva alguns líderes a cargos políticos públicos ou, ainda, a uma reflexão mais profunda sobre a condição social em que vivem. Percebemos que alguns municípios, especialmente os que sofrem mais com o rigor das longas estiagens, têm sindicatos mais combativos e, até mesmo, socialmente mais justos, com vistas a uma reforma agrária (citamos os casos de Quixadá, Canindé e Reriutaba), ao contrário de municípios onde o clima é mais ameno e a estiagem menos rigorosa (casos como os de Guaraciaba do Norte, Ubajara, São Benedito e Varjota).

${ }^{7} \mathrm{O}$ governo federal concede os benefícios àqueles que trabalharem no campo no mínimo 12 anos. Muitos retornados, que não foram bem-sucedidos na migração, voltam na intenção de se aposentar como lavradores, mas, por terem deixado o trabalho do campo e obtido registros em firmas urbanas, não conseguem o benefício, o que é motivo de muita frustração, levando-os, algumas vezes, a uma nova migração.

${ }^{8}$ Ressalte-se que não se trata de um determinismo geográfico, até porque entendemos que em todas estas localidades predomina historicamente a concentração de terras e relações de trabalho alienantes e, muitas vezes injustas. Contudo, nos municípios de clima mais ameno, como os da Serra da Ibiapaba, a população tende a se conformar com as condições em virtude do ambiente proporcionar uma diversidade maior para o trabalho agrícola, de modo que o choque com os proprietários, quando considerado, é sempre postergado. Nestes municípios, por haver concentração de terras, a produção é sempre voltada para a comercialização, com vistas ao suprimento da demanda para outros municípios e não para a subsistência. Mas como esta fórmula traz a oferta de empregos, os movimentos sociais, especialmente os sindicatos, acabam desmobilizados. 
Em alguns municípios, a agricultura é uma atividade muito lucrativa, conforme verificamos na fala do Sr. Deusdete que também foi vereador no seu município por três mandatos pelo PSDB:

\begin{abstract}
A agricultura hoje dá o retorno financeiro bom, você trabalhando com organização, você consegue ter um retorno bom. Principalmente nesta área que sustenta a nossa Guaraciaba, que são as hortaliças. Guaraciaba é responsável por $70 \%$ das hortaliças consumidas no estado do Ceará. É o maior produtor de hortaliças do estado. (...) Eu planto mais especificamente tomate (...) graças a Deus, quando a gente acerta numa "hortazinha" de tomate dá o que um vereador não tira nos quatro anos de mandato. (Sr. Deusdete, retornado maduro do Rio de Janeiro, morador de Guaraciaba do Norte e presidente do Sind. Trab. Rurais deste município - entrevista concedida em janeiro de 2006)
\end{abstract}

Em toda sua entrevista não há um apelo à reforma agrária, apesar de se tratar do presidente do sindicato da classe trabalhadora e de ser do conhecimento de todos que as terras do município estão concentradas nas mãos de poucos agricultores.

Cabe ressaltar que, segundo a observação dos próprios retornados e de autoridades locais, a agricultura em ascensão tem, até mesmo, evitado que a migração ocorra, especialmente nos municípios da serra da Ibiapaba.

O Rio de Janeiro hoje (...) não é mais o Rio de Janeiro de antigamente onde saía muitas pessoas daqui (...) e conseguiu lá fazer a vida, ganhar dinheiro, montar restaurante, crescer. Hoje não dá, mal dá "pra" sobreviver... Eu sempre oriento (...) é bobagem vocês irem para o Rio de Janeiro "pra" irem trabalhar numa cozinha ganhar um salário mínimo porque hoje aqui vocês já "tão" tirando quase um salário mínimo e é livre: o pessoal lá da zona rural "tão" tirando duzentos e sessenta reais por mês (...) com o domingo livre, após as dezesseis horas é livre, sem aquela escravidão. Porque você lá no Rio de Janeiro você é um escravo do trabalho, do trânsito, do chefe. Aqui não! Tem as tolerâncias, a amizade. Tanto é que a gente presencia, hoje poucos jovens vão para o Rio de Janeiro, coisa que há alguns tempos atrás era demais, o pensamento do povo era completar dezoito anos e ir para o Rio de Janeiro. (Deusdete, presidente do Sind. Trab. Rurais Guaraciaba do Norte e retornado - entrevista em janeiro de 2006) 
A ação pontual do governo no nível federal e as práticas agrícolas mais recentes têm levado alguns municípios a verem na agricultura um forte mantenedor econômico. Neste sentido, também é um caminho possível para a reterritorialização econômica de alguns retornados. Todavia, além do aspecto econômico, retomando o que deixamos em aberto há pouco, há um elemento político importante. Nos municípios onde a agricultura tem subsídios e dá resultados positivos para o mercado, o Sindicato de Trabalhadores Rurais serve também como um degrau político, como é o caso do próprio Sr. Deusdete, mencionado acima.

A partir do nosso trabalho de campo, podemos afirmar que existe uma relação entre o retorno e uma maior participação política, configurando mais um aspecto que evidencia os reflexos da multiterritorialidade do retornado. A participação em movimentos sociais organizados, como o dos Sindicatos de Trabalhadores Rurais, é um exemplo. Sem cair numa romantização do sujeito retornado, entendemos que essa maior conscientização também é uma estratégia de sobrevivência para uns - a maior parte dos retornados que voltam para a agricultura - $\mathrm{e}$ uma oportunidade de viabilizar projetos pessoais ${ }^{9}$ para outros.

Entre as consequências advindas do processo de reterritorialização do migrante retornado, ainda que carregada de um aspecto simbólico, percebemos ainda, durante nossa pesquisa de campo, que os locais de retorno sofreram um aumento da violência ou, ao menos, um aumento na percepção de violência, muitas vezes ligada simbolicamente à figura de alguns retornados, que servem assim como uma espécie de "bode expiatório".

Evidências do aumento da violência, não obrigatoriamente, é claro, ligada à presença dos retornados, são recomendações como a de que, em saídas noturnas, não se vá de moto para lugares afastados, e mesmo em veículos grandes como pick-ups, pois haveria constantes assaltos seguidos de violência física. Segundo muitas entrevistas, grande parte desses atos seria praticada por migrantes retornados do Rio de Janeiro ou de São Paulo, geralmente jovens, como presenciamos num trabalho de campo em julho de 2005.

9 Em todos os municípios pesquisados, os STTR (Sindicatos de Trabalhadores e Trabalhadoras Rurais) são as entidades não governamentais mais bem estruturadas, quando não são as únicas entidades desse caráter nos municípios. Vale lembrar que todos os STTRs são inter-relacionados e possuem vínculos com entidades maiores desta categoria, como o MST e a CONTAG. 
Não é fato isolado a participação de migrantes nordestinos no tráfico de drogas nas comunidades populares do Rio de Janeiro, ${ }^{10}$ e parece não ser mera coincidência o aumento da violência e o aumento do retorno, mas devemos considerar que as drogas nestes lugares não foram levadas pelos retornados, como diagnosticam os moradores não migrantes e os migrantes retornados maduros, tendo em vista, sobretudo, estarem esses municípios entre o chamado "Polígono da Maconha" (no vale do rio São Francisco) e capitais de maior consumo como Fortaleza e Teresina. Também é nítido que o retornado tem sofrido uma estigmatização nos lugares de retorno, sobretudo o jovem, visto, muitas vezes, como aquele que traz a violência e, consequentemente, "corrompe" as mentalidades locais, permeando esses lugares de conteúdos negativos provenientes da metrópole.

Podemos concluir, portanto, que o tráfico de drogas e a criminalidade, como meios econômicos de subsistência, são elementos muitas vezes reforçados pela presença dos retornados, uma face mais cruel da multiterritorialidade que o contato com as metrópoles ajuda a constituir. Tais territorialidades são forjadas na vivência de territórios de "baixa intensidade":

Baixa intensidade, podemos dizer, porque eles não implicam grandes transformações espaciais, nem mesmo, na maioria das vezes, alterações físicas mais visíveis nas "formas" da cidade. Estão relacionados à construção territorial que fazemos através das funções que desempenhamos e das significações que propomos através de nossos movimentos no interior dos espaços urbanos. (HAESBAERT, 2004, p. 350)

Dessa maneira, podemos dizer que os retornados cearenses vivenciam uma multiterritorialidade comum a todos os migrantes, através da construção de territórios-rede, mas também são suscetíveis de distintas

${ }^{10}$ No ano de 2005, por exemplo, a polícia carioca matou o bandido "Bem-te-vi", chefe do tráfico de drogas na Rocinha. O traficante nascera em Ipu, município vizinho a Guaraciaba do Norte e, segundo moradores locais, "dava emprego" a diversos conterrâneos.

${ }^{11}$ De modo semelhante ao que ocorre de forma muito mais grave com os "regressados" angolanos em Luanda, ao retornarem do Congo, após o fim da guerra civil em Angola, conforme nos relata Pereira (1999:123): "Os regressados foram associados ao mercado paralelo, portanto, ao comércio ilegal, ao contrabando, à extorsão e à delinquência. Deparando-se com a desagregação dos serviços públicos e a generalização da corrupção em todos os setores da vida social, a sociedade luandense responsabiliza os regressados por introduzirem a pequena corrupção e os métodos do 'desenrascar-se' que, cedo ou tarde, tornaram-se prática comum em Luanda". Entendemos, contudo, que o caso angolano é muito mais radical e envolve elementos (como questões étnico-nacionalistas) que tornariam inapropriada uma analogia mais direta. 
experiências individuais multiterritorializantes, muito comuns nas grandes metrópoles. Experiências que levam os migrantes, algumas vezes, a viverem situações muito positivas, como o acesso a boas universidades, ou muito negativas, como as mencionadas acima.

Esta análise da reterritorialização do retornado cearense está certamente incompleta, sobretudo porque seria impossível dar conta de um processo que está prenhe de possibilidades, no qual a multiplicidade e a instabilidade são características básicas. Seria muita pretensão nossa desvendá-la em sua totalidade, mas, partindo de uma análise geográfica com ênfase na observação de campo e dando voz ao agente em questão, o retornado, cremos que conseguimos apreender alguns traços fundamentais desses sujeitos, tão singulares e emblemáticos do nosso tempo e espaço.

\section{Conclusão}

A migração de retorno é um movimento tão frequente entre populações que têm historicamente migrado, que parece banal, para os retornados, buscar uma resposta para seu movimento. O movimento de retorno que se processa atualmente, contudo, se dá por motivos específicos ao nosso espaço-tempo. Condições históricas, atualmente, têm promovido um retorno de migrantes em escala global. $\mathrm{O}$ avanço das tecnologias especialmente de transporte - no estágio atual do capitalismo tem proporcionado retornos mais rápidos aos territórios de origem e, em certo sentido, favorecido certa homogeneização dos territórios.

O retorno muitas vezes parece ser o reflexo de uma territorialidade voltada mais à mobilidade que à fixação, o que pode ser visto como uma característica dos novos sujeitos da chamada pós-modernidade. As inúmeras idas e vindas, aparentemente sem um propósito muito definido, levavam a crer que os migrantes eram impulsionados por um "espírito aventureiro", individual ou de grupo, que os mantinha em constante movimento, ou, de maneira mais estrutural, subordinados às contingências do capitalismo globalizado. Ficou nítido, entretanto, que a territorialidade do retornado não pode ser vista simplesmente como móvel ou estática, individual ou "estrutural", mas como uma territorialidade múltipla ou multiterritorialidade, constituída, sobretudo, por este ir e vir em busca de melhores condições de vida, que também são múltiplas, compreendidas não somente pela esfera econômica, mas por todas elas conjuntamente, ressaltando-se aí a dimensão simbólica, o conjunto de valores e identificações que os constituem enquanto sujeitos. 
A múltipla identidade territorial do retornado se complexifica principalmente pelos contatos com o lugar de imigração. E é de volta ao lugar de origem que o retornado revela, normalmente de modo espontâneo, o fruto dessa hibridização. A mistura de hábitos revela uma verdadeira "multiculturalização". É no bojo desse processo que se dá, hoje, a constituição de uma identidade nordestina.

Ao migrar, o cearense não se percebe, ou não se intitula, nordestino. Para muitos que saem, a migração é a primeira experiência de distanciamento do território de origem. Logo, não há ainda, de modo claramente formulado, uma noção de pertencimento relativa a uma escala espacial que extrapole aquela do seu local de origem. É no local de imigração que o cearense se descobre, de modo mais concreto, como nordestino, especialmente através do olhar que o outro, no "Sul" (Sudeste), lhe concede (PÓVOA NETO, 1994). O encontro com migrantes de outros lugares da mesma região, além da segregação socioespacial a que são submetidos os indivíduos com perfil econômico e cultural semelhante, faz com que os migrantes cearenses se percebam também com uma identidade territorial nova, a identidade nordestina. Nova no sentido empírico, na vivência de uma territorialidade que une indivíduos com experiências diferenciadas nos lugares de origem, mas que acabam constituindo uma identificação comum nos lugares de imigração.

A situação de carência muitas vezes extrema nas comunidades para onde se direcionam os migrantes nas grandes metrópoles configura o que Haesbaert (2004) chamou de "aglomerados de exclusão" que, para além de lugares de exclusão, são, na verdade, espaços de inclusão precária onde os migrantes, parcialmente desterritorializados, buscam formas particulares e instáveis de recriar seus lugares de origem, alimentados por suas "geografias imaginárias" - depois recompostas durante o processo de migração de retorno.

Ao longo do estudo, fez-se necessário ressaltar algumas diferenças, o caráter heterogêneo do grupo dos retornados, de modo que pudéssemos melhor compreendê-los. Sem ter a pretensão de esgotar as possibilidades de análise, de dar conta exaustivamente do fenômeno ou de criar classificações definitivas, tentamos separá-los em, pelo menos, dois grupos distintos com base na faixa etária, tanto no sentido dos espaços de imigração quanto nos de retorno. Distinguimos assim os diferentes momentos do processo migratório.

Os retornados com os quais tivemos contato, em geral pertencentes a uma mesma classe social, apresentaram-se, assim, especificados em pelo menos dois grupos básicos: o primeiro, referido aos retornados maduros, 
cuja migração foi realizada sobretudo num período de maior intervenção do Estado, especificamente no período conhecido como "desenvolvimentista" ou do chamado "milagre brasileiro". Na verdade, não definimos uma faixa etária exata porque entendemos que este fluxo migratório se manteve mesmo após esse período, o que estendeu a faixa etária com que percebemos estes migrantes, abarcando pessoas que estavam em torno dos 50 anos em diante. $\mathrm{O}$ segundo grupo se referiu aos retornados jovens, definidos sobretudo em função da migração mais recente, que hoje ainda domina o fluxo migratório Nordeste/Sudeste. Muitos partem ainda antes da maioridade e, geralmente, retornam por pouco tempo. Alguns retornam acreditando que tornarão a migrar, o que podem fazer pouco tempo depois, enquanto outros se mostram desiludidos com a migração e decidem não mais voltar, o que, muitas vezes, não se concretiza. Apesar do desânimo, a ilusão de "progresso", em muitos casos, empurra-os a uma nova migração, resultando, a posteriori, em mais um retorno.

Nas idas e vindas dos retornados, os lugares de origem vão sendo transformados de forma distinta, conforme os retornados sejam mais antigos ou mais recentes, mais jovens ou mais maduros. Os jovens e recém-chegados tendem a provocar mudanças mais visíveis e contundentes. Muitos retornados mais antigos e hoje já maduros, mesmo tendo se reterritorializado ainda jovens, já estão espacialmente tão vinculados ao lugar de origem que muitas vezes pouco se diferenciam daqueles que nunca migraram, inclusive aconselhando muitos jovens desses lugares a não migrar, considerando "não valer a pena". Por outro lado, outros, que retornam já maduros, com o intuito principal de melhor aproveitar a aposentadoria, acabam muitas vezes estimulando a migração daqueles que nunca saíram.

Com os retornados jovens parece ser comum, assim como ocorreu com os migrantes maduros no passado, uma certa indefinição quanto ao lugar a ser estabelecido para uma efetiva territorialização, de caráter mais estável. É claro que não se trata de uma propensão ligada apenas a uma característica da juventude, pois devemos levar em consideração que o próprio momento histórico-econômico do país entre as décadas de 1990 e 2000 se alterou em relação ao período de 1960 a 1980.

Vimos também que a reterritorialização dos retornados nos seus lugares de origem é caracterizada pela multiplicidade, o que indica que sua territorialidade resulta da imbricação de territorialidades múltiplas experimentadas e acumuladas no decorrer de suas idas e vindas. Ocorre uma mescla da territorialidade "primeira" ou "original", hoje na memória, 
com territorialidades "posteriores" ou "segundas" (não obrigatoriamente "secundárias"), fruto, sobretudo, da vivência de múltiplos territórios na metrópole. Nesta vivência metropolitana, o retornado experimenta novas possibilidades de construção territorial e de significação do mundo, transformando profundamente sua territorialidade "primeira" ou "original".

Sua identificação com o mundo é, portanto, consideravelmente modificada. Surge daí o que Haesbaert denominou de multiterritorialidade, uma multiterritorialidade que se manifesta muitas vezes no plano individual, mas que, nem por isso deixa de estar vinculada a uma multiterritorialidade mais ampla ligada às diversas redes sociais construídas ao longo dos circuitos migratórios. Vale ressaltar que a multiterritorialidade não se torna visível apenas a partir do processo de retorno. A migração em sentido amplo já implica a vivência de uma multiterritorialidade. Por mais reclusos que os migrantes permaneçam na metrópole, sempre ocorrem experiências - no ambiente de trabalho, por exemplo - que permitem criar estratégias que acabam construindo múltiplos significados em relação ao espaço ali vivido, experiências que estimulam, ou não, o próprio retorno.

Mesmo que o migrante retornado não volte a migrar, realizando apenas um ciclo de migração e retorno, a multiterritorialidade que ele vivencia lhe serve sempre, de alguma forma, como um "trunfo" que the concede uma espécie de "capital simbólico" nas estratégias de sobrevivência frente aos grupos locais. Nem por isso essa multiterritorialidade, como foi destacado neste trabalho, envolve apenas aspectos positivos. Observamos que a violência, mais comum nas grandes metrópoles, também atinge os municípios de origem dos retornados. Evidentemente devem ser guardadas as devidas proporções, mas, segundo a percepção de alguns retornados, o aumento da violência, especialmente aquela ligada ao tráfico de drogas, estaria ligado ao retorno de alguns migrantes que tiveram na sua vivência metropolitana participação no mundo do narcotráfico e/ou dos circuitos ilegais da economia. Muito cuidado deve-se ter, neste caso, a fim de se combater a estigmatização genérica do migrante retornado como agente dessa transformação social negativa.

Para finalizar, gostaríamos de reafirmar o papel da "multiterritorialização" do migrante retornado enquanto um "trunfo" nos seus processos de reterritorialização, multiterritorialidade entendida aqui tanto no seu sentido funcional, mais concreto - quando o migrante participa ativamente do processo de abertura de novas territorialidades, fortalecendo uma multifuncionalidade econômica, por exemplo — , quanto 
no sentido mais simbólico, incorporando novos valores e novas referências territoriais à sua reprodução enquanto grupo nos antigos territórios de origem - que, desse modo, podem ser profundamente transformados. No entanto, nessa transformação, não se podem separar as relações estruturais na ordem da economia e da política nacionais-internacionais das relações cotidianas, que fazem do migrante retornado, em parte, também, um ativo sujeito des-reterritorializador.

\section{A RETERRITORIALIZAÇÃO DO RETORNADO CEARENSE: UMA PERSPECTIVA GEOGRÁFICA}

Resumo: O presente momento da humanidade tem proporcionado o surgimento de um vasto número de agentes sociais que, por força do contexto socioeconômico, constituem-se novos sujeitos. No bojo dessas mudanças econômicas e sociais globais, os migrantes laborais estão entre os sujeitos que mais sofrem e causam transformações espaciais. O presente trabalho investiga o migrante no seu processo de retorno, o migrante retornado, tendo por objetivos identificar elementos motivadores para o retorno, sua ação espacial transformadora no lugar de retorno e mostrar que o peso simbólico do lugar de origem influencia decisivamente no processo. Buscou-se assim apresentar como se dá a reterritorialização deste indivíduo no seu lugar de retorno. Em função das condições da pesquisa e das limitações para a investigação, a escala de estudo foi reduzida aos limites de alguns municípios no interior do Ceará, entendendo que este estado se constitui como um dos grandes polos de emigração inter-regional do Brasil e hoje se delineia como um dos grandes receptores de migrantes de retorno. Sendo assim, o migrante retornado assume feições características de quem incorporou elementos dos territórios distintos onde estabeleceu sua territorialidade, constituindo-se, portanto, em um sujeito multiterritorial. Por fim, o retornado cearense, através de sua territorialidade, é visto, para além dos estigmas e estereótipos de migrantes, como sujeito social relevante e, em parte, também, um agente de seu destino.

Palavras-chave: Des-reterritorialização; multiterritorialidade; migração de retorno; migração interna no Brasil

\section{RETERRITORIALIZATION OF RETURNED MIGRANTS IN CEARÁ STATE: A GEOGRAPHICAL APPROACH.}

Abstract: The contemporary social moment has provided the emergence of a vast number of new social subjects. Regarding these global economic and social changes, labor migrants are one of these subjects who endure and generate spatial transformations the most. This article takes this 
situation into consideration, by investigating the migrant in his return process, in other words, as returned migrant. It aims to identify motivating elements for the return process, its changing action in the place of return and also to show how the symbolic weight of the place of origin influences decisively in this process. It has been attempted to present, therefore, how their re-territorialization, in their place of return, occurs . Under the research terms and the limitations for the investigation, the study scale was reduced to the limits of some municipal districts of Ceará, in Brazil, highlighting that this state is considered one of the greatest inter-regional emigration Brazilian nodes and nowadays it is one of the great receivers of returned migrants. So, this returned migrant takes over specific features by incorporating elements of distinct territories where he had established his territoriality along his trajectory, constituting himself, then, a multiterritorial subject. Finally, the returned migrant from Ceará is seen, far beyond migrants' stigmas and stereotypes, as a relevant social subject and agent of his destiny.

Keywords: De-territorialization; multi-territoriality; return migration; Brazilian internal migration

\section{BILBIOGRAFIA}

ALBUQUERQUE Jr, Durval Muniz de. (1999) A invenção do Nordeste e outras artes. Cortez. São Paulo.

CASTRO, I. (1992) O mito da necessidade: discurso e prática do regionalismo nordestino. Bertrand Brasil. Rio de Janeiro

DIAS, Juliana Braz. (2000) A volta do filho próspero: emigrantes caboverdianos retornados e seus familiares. In: Teixeira, C. C. (org.) Em busca da experiência mundana e seus significados. Relume Dumará. Rio de Janeiro.

GAUDEMAR, Jean-Paul de. (1977). Mobilidade do trabalho e acumulação do capital. Estampa. Lisboa.

HAESBAERT, Rogério. (2004) O mito da desterritorialização. Bertrand Brasil. Rio de Janeiro.

. (2005) Da desterritorialização à multiterritorialidade. Anais do X Encontro de Geógrafos da América Latina. USP. São Paulo.

. (2007) Território e multiterritorialidade. GEOgraphia. Revista do Programa de Pós-Graduação em Geografia UFF. Ano IX, nº 17, p.19-46, 2007. Niterói. 
IANNI, Otávio. (1992) A idéia de Brasil moderno. Brasiliense. São Paulo. PEDONE, Claudia. (2000) El trabalho de campo y los métodos cualitativos: necessidad de nuevas reflexiones desde las geografías latinoamericanas. Scripta Nova 57, $1^{\circ}$ de febrero. Acessível em: http://www.ub.es/geocrit/sn-57.htm.

.(2000b) El papel que cumplen las cadeñas y las redes en la conformación de las trayectorias espaciales y estrategias migratorias. Scripta Nova 69(49), $1^{\text {o }}$ de agosto. Acessível em: http:// www.ub.es/geocrit/sn-69-49.htm.

(2002) El Potencial del análisis de las cadeñas y redes migratórias em las migraciones internacionales contemporáneas. In Cataño, J. G.; López, C. M. (eds), Atas del III Congreso sobre la Inmigración en España. Contextos y Alternativas. Laboratorios de Estudios Interculturales, Vol. II, pp. 223-235. Granada.

PEREIRA, Luena Nascimento Nunes.(1999) Os regressados na cidade de Luanda: um estudo sobre a identidade étnica e nacional em Angola. Programa de Pós-graduação em Antropologia Social. USP. Dissertação de mestrado. São Paulo

PÓVOA NETO, Helion. (1994) A produção de um estigma: nordeste e nordestinos no Brasil. Revista Travessia: Revista do Migrante, v. 7, n. ${ }^{\circ}$ 19, p. 20-22, maio/agosto. São Paulo.

VALVERDE, Joaquín R. (2004) Las migraciones internas de retorno en España durante la primera mitad de la década de los noventa: implicaciones demográficas y territoriales. Scripta Nova, 157, 15 de janeiro. Acessível em: http://www.ub.es/geocrit/sn-157.htm. 